\title{
Research on Logistics Efficiency in East China Based on Three-Stage DEA Model
}

\author{
Kun Jiang \\ School of transportation, Shanghai maritime university, Nan Hui new town, Pu dong new area, \\ 201306 China. \\ $18616294706 @ 163 . c o m$
}

\begin{abstract}
The three-stage DEA model is used to eliminate the environmental influence and random interference, according to variable scale compensation $\left(B C^{2}\right)$ research and evaluation of logistics efficiency in east China from the perspective of investment. In this paper, 5 environment variables, especially education, are developed as environment variables. The results show that there is no significant difference in the efficiency of pure technology, and the main difference is in the efficiency of scale.
\end{abstract}

Key words: logistics efficiency, Three-stage DEA model, Pure technical efficiency, the scale efficiency

\section{Introduction}

With the rapid development of urban economy, the social division of labor has been increasingly refined, and the logistics industry has increasingly become an important driving force for the development of social economy. When the domestic economy enters the "new normal", two characteristics of the logistics industry's development are on the one hand, the market growth of the logistics industry is slowing down, on the other hand, its service level is steadily improving [1]. The efficiency of logistics operation is closely related to the effective investment and the overall professional quality of employees.East China consists of Shanghai, jiangsu, shandong, zhejiang, fujian, jiangxi, anhui and Taiwan provinces.Due to the difficulty in collecting relevant data from Taiwan province and the difference in statistical standards, Taiwan province is not included in the evaluation objects.After 40 years of rapid development of reform and opening up, the economic contribution of east China to the national economic growth has been very positive.So also can say in east China to enhance the efficiency of logistics also play an important role for the national logistics industry development, so the efficiency evaluation of regional logistics also has great practical significance, has positive significance in enhancing the logistic efficiency of various provinces and cities.

Published in 2001 in our country "law of the People's Republic of China national standard logistics term of logistics is defined: in the land of goods from the supplier to accept the entity flow process, according to the actual need, transportation, storage, loading and unloading, handling, packaging, circulation processing, distribution, information processing, etc, on the basis of the organic combination of the basic function realization of user requirements [2].

Logistics industry can include transportation industry, storage industry, post administration industry, packaging industry, loading and unloading industry, circulation processing industry, logistics information industry and other seven departments [3] However, due to the strong correlation between each link, it can be divided into transportation, storage and postal services.

\section{Research Methods and Data Description}

\subsection{Initial Efficiency of Traditional DEA Model Analysis}

In 1978 by the famous operational researcher A. c harness first proposed a known as Data Envelopment analysis (Data Envelopment analysis, DEA model for short) method, is used to evaluate the same division between the relative effectiveness of DEA efficient [4]. Banker, et al. made a $\mathrm{B} C^{2}$ model, the $C^{2} R$ model of the comprehensive technical efficiency is decomposed into scale 
efficiency and pure technical efficiency. DEA model is divided into input-oriented and input-oriented, and different directions can be chosen according to specific analysis purposes. This paper choose investment direction $\mathrm{BC}^{2}$ efficiency evaluation model.

\subsection{SFA Regression}

We mainly focus on the relaxation variable $[x-X \lambda]$ and think that the relaxation variable can reflect the initial low efficiency, which is composed of environmental factors, management inefficiency and statistical noise.

It is necessary to adjust the decision unit to the same external environment and random factors without the influence of environmental factors and random factors on the efficiency value. The decision unit in the worst external environment is the standard. For all other decision units in relatively good external environment, the adjustment method of increasing their input is selected, and for each decision Yuan investment adjustment is as follows: $X_{n i}^{A}=X_{n i}+\left[\max \left(f\left(z_{i} ; \beta_{n}\right)\right)-\right.$ $\left.f\left(z_{i} ; \beta_{n}\right)\right]+\left[\max \left(v_{n i}\right)-v_{n i}\right] i=1,2, \cdots, I ; n=1,2, \cdots, N$

$X_{n i}^{A}$ is adjusted input, $X_{n i}$ is before the adjustment, $\left[\max \left(f\left(z_{i} ; \beta_{n}\right)\right)-f\left(z_{i} ; \beta_{n}\right)\right]$ the adjustment of the external environment $\left[\max \left(v_{n i}\right)-v_{n i}\right]$ put all decision-making units at the same level of luck.

In this paper, Joe drew [5] et al. (Jonrow, et al.) Method to estimate the $\mathrm{E}\left[v_{n i} \mid v_{n i}+\mu_{n i}\right]$ and random error estimate $v_{n i}$ calculation formula is:

$$
\mathrm{E}\left[v_{n i} \mid v_{n i}+\mu_{n i}\right]=s_{n i}-f\left(z_{i} ; \beta_{n}\right)-E\left[u_{n i} \mid v_{n i}+u_{n i}\right] n=1,2, \cdots, N ; i=1,2, \cdots, I
$$

\subsection{DEA Efficiency Analysis of Input and Output Variables after Adjustment}

The adjusted input and output variables are used to calculate the efficiency of each decision unit again. At this time, the efficiency has been eliminated the influence of environmental factors and random factors, which is relatively true and accurate.

\section{Input and Output Indicators and Data Sources of Environmental Variables}

The DEA[4]Methods there are many types of literature on logistics efficiency evaluation[5][6][7].

In this paper, transportation, storage and postal workers, as well as fixed asset investment, are taken as the input variables of logistics.In terms of output indicators, the freight volume of each province (city) is one of the output indicators.

At the same time, the logistics freight turnover of each province is taken as the second output variable.In the selection of environmental variables, the principle that environmental variables affect the efficiency value is not within the subjective control range of the sample.

According to the above principles, this paper selects the road network density of each province [8] Education development [5] Factors such as government support, urbanization level, residents' disposable income, etc. are taken as environmental variables. The above data can be obtained from the statistical yearbooks of provinces and cities and China 2014-2015.

\section{Empirical Results Analysis}

Variable scale compensation for logistics efficiency in 7 provinces and cities in eastern China using DEAP2.1 software $\left(\mathrm{BC}^{2}\right)$, meanwhile, the logistics efficiency of various provinces and cities is analyzed without considering the influence of environmental factors and random errors. The results are shown in table 1. 
Table 1. Logistics Efficiency before Adjustment in East China from 2014 to 2015

\begin{tabular}{ccccccccc}
\hline region & TE1 & PTE1 & SE1 & Scale reward & TE1 & PTE1 & SE1 & Scale reward \\
\hline Shanghai & 1 & 1 & 1 & - & 1 & 1 & 1 & - \\
shandong & 0.315 & 0.427 & 0.739 & IRS & 0.377 & 0.454 & 0.831 & IRS \\
jiangsu & 0.367 & 0.448 & 0.821 & IRS & 0.377 & 0.468 & 0.806 & IRS \\
anhui & 1 & 1 & 1 & - & 1 & 1 & 1 & - \\
jiangxi & 0.565 & 1 & 0.565 & IRS & 0.619 & 1 & 0.619 & IRS \\
zhejiang & 0.469 & 0.652 & 0.719 & IRS & 0.661 & 0.694 & 0.952 & IRS \\
fujian & 0.32 & 0.87 & 0.368 & IRS & 0.476 & 0.877 & 0.543 & IRS \\
mean & 0.577 & 0.771 & 0.744 & & 0.644 & 0.785 & 0.822 & \\
\hline
\end{tabular}

Note: TE1 is the comprehensive efficiency value of the first stage, PTE1 is the pure technical efficiency value of the first stage, SE1 is the scale efficiency value of the first stage, TE1=SE1*PTE1. IRS, DRS, and -- represent incremental, decreasing, and constant returns to scale.

From table 1 can follow without considering the random noise and environmental factors, the 2014-2015 in east China provinces and cities logistics comprehensive technical efficiency mean value is $0.577,0.644$ respectively, the pure technical efficiency is $0.771,0.785$, scale efficiency of 0.744 and 0.822 . In general, it can be concluded that the main efficiency indicators of east China from 2014 to 2015 have been gradually improved, among which Shanghai and anhui have three efficiency values of 1 , which are at the forefront of efficiency.

Table 2. Regression Results of SFA Model

\begin{tabular}{c|c|c|c}
\hline & & Labor input is slack & Slack capital investment \\
\hline Constant term & 2014 & $1.63 \mathrm{e}+02^{* * *}$ & $1.62 \mathrm{e}+03^{* * *}$ \\
\hline The density of road network & 2015 & $1.51 \mathrm{e}+02^{* * *}$ & $8.00 \mathrm{e}+03^{* * *}$ \\
\hline & 2014 & $1.10 \mathrm{e}+00^{* * *}$ & $1.95 \mathrm{e}+01^{* * *}$ \\
\hline Education situation & 2015 & $7.73 \mathrm{e}-01^{* * *}$ & $1.47 \mathrm{e}+01^{* *}$ \\
\hline Government support & 2014 & $7.53 \mathrm{e}-01^{* *}$ & $6.53 \mathrm{e}+02^{* * *}$ \\
\hline & 2015 & $6.60 \mathrm{e}+00^{* *}$ & $2.23 \mathrm{e}+03^{* *}$ \\
\hline urbanization & 2014 & $2.83 \mathrm{e}-01^{* * *}$ & $7.96 \mathrm{e}+00^{* * *}$ \\
\hline & 2015 & $1.27 \mathrm{e}-01^{* * *}$ & $4.81 \mathrm{e}+00^{* * *}$ \\
\hline Household disposable income & 2014 & $1.39 \mathrm{e}+02^{* * *}$ & $7.99 \mathrm{e}+03^{* * *}$ \\
\hline$\sigma^{2}$ & 2015 & $2.15 \mathrm{e}+02^{* * *}$ & $1.37 \mathrm{e}+04^{* * *}$ \\
\hline$\gamma$ & 2014 & $1.67 \mathrm{e}-03^{* * *}$ & $1.43 \mathrm{e}-02^{* * *}$ \\
\hline $\log L$ & 2015 & $1.09 \mathrm{e}-03^{* * *}$ & $9.61 \mathrm{e}-02^{* * *}$ \\
\hline & 2014 & $6.06 \mathrm{e}+00^{* * *}$ & $2.41 \mathrm{e}+05^{* * *}$ \\
\hline LR & 2015 & $7.54 \mathrm{e}+00^{* * *}$ & $2.36 \mathrm{e}+05^{* * *}$ \\
\hline & 2014 & $0.999^{* * *}$ & $0.999^{* * *}$ \\
\hline & 2015 & $0.999^{* * *}$ & $0.999^{* * *}$ \\
\hline & 2014 & $1.09 \mathrm{e}+01$ & $4.78 \mathrm{e}+01$ \\
\hline & 2015 & $1.22 \mathrm{e}+01$ & $4.86 \mathrm{e}+01$ \\
\hline & 2014 & $4.53 \mathrm{e}+00$ & $4.43 \mathrm{e}+00$ \\
\hline & 2015 & $3.40 \mathrm{e}+00$ & $2.89 \mathrm{e}+00$ \\
\hline
\end{tabular}


Note: $* * *$ and $* *$ respectively indicate that they are significant at the significance levels of $10 \%$, $5 \%$ and $1 \%$ in the $\mathrm{t}$ test. $\sigma^{2}=\sigma_{u}^{2}+\sigma_{v}^{2}$

The second stage of the sales force automation (SFA) regression, regression results with Ffontier4.1 software, specific results are shown in table 2, at the same time can be seen from table 5 the environment variable for labor and capital investment both slack variable regression coefficient through the test of significance.

\subsection{Road Network Density}

Road network density to a certain extent, shows the clear on the regional traffic condition, the coefficient in the 2014-2015 on the relationship between the labor and capital investment slack variables are negative, and through the test of significance of $1 \%$, so it can be concluded that the influence of the road network density for two slack variable is positive. With the continuous improvement of the infrastructure such as roads, railways and water transportation lines in various provinces and cities, the continuous improvement of traffic accessibility is beneficial to the development of logistics industry. As the "One Belt And One Road" initiative continues to be implemented, and the key step is the development of transportation, the mode of multimodal transport is also getting more attention and development.The increase of road network density can better facilitate the connection of various modes of transportation, so as to improve the integration of transportation and reduce the redundancy of labor and fixed assets.

\subsection{Education Development}

The continuous improvement of education level illustrates the various provinces and cities by the rising number of education personnel, have a good influence to improve the quality of the regional labor aspects, from the table can be concluded that education level of capital input redundancy coefficient is negative, and illustrates the education level in improving the quality of the labor force at the same time, also to some extent reduced the capital input redundancy, improve the level of economic decision-making.But at the same time in labor input redundancy coefficient is positive, that logistics industry development situation, the improvement of education level does not have a positive impact on logistics, shows the use of education resources on the one hand there is room for improvement, on the other hand with the development of logistics industry docking is not so good.

\subsection{Government Support}

Government support can be measured by logistics fiscal policy, but is different with previous expected fiscal policy of labor input and capital input redundancy coefficients is positive, the two slack variable is not positive impact. This is likely to be on the one hand, as there is no effective use of financial support fund, on the other hand, due to excessive financial support led to the regional logistics industry scale, has caused the improper use of a variety of factors of production.

\subsection{Urbanization Level}

As the rural population continues to enter the cities, the level of urbanization is also increasing. From the table can be concluded that urbanization level from 2014 to 2015 by the start on the input redundancy coefficient is positive to the negative, illustrates by the adverse effect to the beneficial effects of urbanization, and illustrates the urbanization level and quality have been improved, the process of urbanization in the use of Labour and capital resources, more and more important.

\subsection{Disposable Income Of Residents}

From the table, it can be concluded that the impact of disposable income on labor force input redundancy in 2014-2015 was from positive to negative, and the impact on capital input was significantly negative. This indicates that while the disposable income of residents keeps increasing, it also increases the demand for logistics services, which can improve the utilization rate of logistics capital investment.At the same time, the constant optimization of the utilization ratio of fixed assets investment also reduces the redundancy of labor resources investment. 
Table 3. Efficiency Value after Logistics Adjustment in Eastern China in The Third Stage

\begin{tabular}{ccccccccc}
\hline region & TE3 & PTE3 & SE3 & Scale reward & TE3 & PTE3 & SE3 & Scale reward \\
\hline Shanghai & 1 & 1 & 1 & - & 1 & 1 & 1 & - \\
shandong & 0.586 & 0.940 & 0.624 & IRS & 0.73 & 0.904 & 0.808 & IRS \\
jiangsu & 0.799 & 1 & 0.799 & IRS & 0.777 & 1 & 0.777 & IRS \\
anhui & 1 & 1 & 1 & - & 0.889 & 0.889 & 0.889 & IRS \\
jiangxi & 0.467 & 1 & 0.467 & IRS & 0.511 & 1 & 0.511 & IRS \\
zhejiang & 0.694 & 0.968 & 0.717 & IRS & 0.849 & 0.959 & 0.886 & IRS \\
fujian & 0.338 & 0.923 & 0.366 & IRS & 0.479 & 0.958 & 0.5 & IRS \\
mean & 0.689 & 0.976 & 0.710 & & 0.748 & 0.974 & 0.767 &
\end{tabular}

Note: TE3 is the comprehensive efficiency value of the third stage, PTE3 is the pure technical efficiency value of the third stage, SE3 is the scale efficiency value of the third stage, TE3=SE3*PTE3.IRS, DRS, and -- are incremental, decreasing, and constant returns to scale.

From the comparison in table 1 and table 3, it can be concluded that there are different degrees of efficiency changes before and after the input adjustment in east China in 2014. From the perspective of the front edge of comprehensive technical efficiency, anhui and Shanghai have not changed before and after the adjustment in 2014. This indicates that the logistics resources in this area have been effectively utilized. Meanwhile, from the perspective of pure technical efficiency, the adjusted pure technical efficiency of shandong and jiangsu has been greatly improved, thus improving the comprehensive technical efficiency.

According to the comprehensive technical efficiency of provinces and cities, there are great differences in the comprehensive technical efficiency of provinces and cities before and after the adjustment. After the elimination of environmental factors and random noise, shandong, jiangsu, zhejiang and fujian all have different scale of improvement, among which jiangsu has the most obvious degree of improvement.Jiangxi's comprehensive technical efficiency showed a small decrease after the elimination of environmental factors. Due to the change of the efficiency of the adjusted value, so the comprehensive technical efficiency in east China value increased from 0.577 to 0.698 , the pure technical efficiency rose from 0.771 to 0.976 , scale efficiency has fallen slightly, from 0.744 to 0.710 .

From table 1 and table 3 Shanghai and anhui come to the pure technical efficiency and scale efficiency value has not changed, shandong, jiangsu, jiangxi, zhejiang, fujian on the pure technical efficiency values have different degrees of improvement.In terms of scale efficiency, in addition to anhui and Shanghai, other provinces are also declining in different scale after adjustment. It mainly overestimates the efficiency of pure technology and underestimates the efficiency of scale, and overestimates the efficiency of pure technology are lower than the efficiency of scale.From the perspective of scale reward, scale reward has not changed significantly after adjustment, but is still mainly increasing.

From table 1 and table 3 in 2015 in east China logistics efficiency is calculated results it is concluded that the efficiency frontier changed, after exclusion of uncontrollable factors, only Shanghai in frontier, anhui failed to maintain due to scale efficiency change in the frontier.

In general, after adjustment, the comprehensive technical efficiency value increased by 0.103 , the pure technical efficiency value increased by 0.190 , and the scale efficiency value decreased by 0.055 . 
After the adjustment of shandong, jiangsu, zhejiang and fujian, the value of comprehensive technical efficiency increased, indicating that these provinces had low logistics efficiency due to the adverse external environment and had too low estimation. Jiangxi and anhui saw a slight decline after the adjustment, indicating that these provinces had a favorable external environment.

Shanghai in the efficient frontier, so scale efficiency value hasn't changed, other provinces have reduced scale efficiency, namely the existence of scale efficiency to overestimate, the low estimate of pure technology.

\section{Summary}

Increasing the density of the road network can effectively improve the overall logistics efficiency of all provinces and cities and reduce the redundancy of labor and capital investment.Therefore, all provinces and cities should increase investment in railway, highway, shipping and other modes of transportation according to their own traffic development, and increase the density of transportation network and regional traffic accessibility.Effective play scale effect not only benefit from the efficient use of labor resources, but also because of the logistics resources and information rapid transfer to get the reason, thanks to the improvement of road network density.

Improve the level of education, especially improve the ability of research and innovation of higher education, from the data can be concluded that education for labor input redundancy coefficient is significantly positive, indicates that the development of education does not have the effect of reducing the labor input redundancy. In recent years, the number of college graduates has increased, and the number of logistics industry personnel has also increased. Therefore, it is important to improve the level and effective connection between production, study and research, and improve the practical ability of graduates.

Policy support is also play an important role in logistics industry development, in recent years, various provinces and cities also for financial support to improve logistics industry, capital utilization level is not high, however, to improve the efficiency of regional logistics has not played a positive role. Failure is input, so while improve the regional logistics financial policy support, want special attention to capital use efficiency, precise support to improve the efficiency of capital allocation, promote the comprehensive efficiency.

Along with our country economy level unceasing enhancement, the urbanization rate of $58.5 \%$, in east China urbanization level has been improved, now want to improve the quality of urbanization as the main target, narrow gap among regions, the urbanization effect in improving the resource configuration and elements into play, also can get from the data in east China the urbanization level and quality have been improved, gradually reduce Labour and capital input redundancy to play an active role.

To increase the income level of residents will play a positive role in expanding the consumption demand of local residents, which will be conducive to increasing the demand for logistics services.Along with the optimization of consumption structure, the proportion of service consumption increases gradually, which plays a positive role in improving the utilization efficiency of logistics resources, reducing investment redundancy and improving the comprehensive efficiency of logistics.

Integration of resources, play a scale effect, draws a conclusion from the data in the premise of keep the management level gap is not big, want to notice to scale efficiency, more use of computer technology to integrate logistics resources information scattered, breakthrough the limitation of local market, giving full play to the advantages of east China area as a whole, enhance the cooperation between the various provinces and cities, in technical communication, industrial investment scale effect into full play.

\section{References}

[1]. China federation of logistics and purchasing. China logistics yearbook (2015). Beijing: China materials press.2015. 
[2]. Cheng shuqiang, liu yannan. Dynamic study of agricultural products logistics efficiency and inter-provincial differences in western China -- based on dea-malmquist index method [J]. Statistics and information .2017,32(04):95-101.

[3]. National standard of the People's Republic of China - logistics terminology [J]. Traffic construction and management,2007(10):106-120.

[4]. Fried H O, Lovell C A K, Schmidt S, Yaisawarng S. Accounting for environmental effects and statistical noise in data envelopment analysis [J]. Journal of Productivity Analysis, 2002,17 (2) : 157-174.

[5]. Jondrow J, Materov I, Lovell C A K, Schmidt P. On the estimation of technical inefficiency in the stochastic frontier production model [J]. Journal of Econometrics, 1982, 19 (2/3) : $233-237$.

[6]. Guo junhua, ni Ming, li bangyi. Research on agricultural production efficiency based on threestage DEA model [J]. Quantitative economy,2010,27(12):27-38.

[7]. Wang guangming. Logistics efficiency evaluation of provinces and cities along China's maritime silk road [D]. Zhongbei university,2016.

[8]. Benchmarking the operational efficiency of the third party logistics providers using data envelopment analysis[J].Supply Chain Management: An International Journal,2006,11(3):259265.

[9]. Wang qin-mei and tan cui'e. An empirical study on logistics efficiency and its influencing factors in xi 'an - based on DEA model and TobitAnalysis of model [J]. Soft science, 2013, 27(05):7074. 